\title{
CRITERIOS ULTRASONOGRÁFICOS DEL EMBARAZO ECTÓPICO
}

\section{ULTRASONOGRAPHIC CRITERIA FOR ECTOPIC PREGNANCY}

\author{
Luis Alberto Carpio Guzman 1,a
}

\begin{abstract}
RESUMEN
El embarazo ectópico es una patología ginecobstétrica cuyo manejo ha cambiado en la actualidad, pasando de ser una patología de manejo netamente quirúrgico a una entidad de manejo médico con indicaciones quirúrgicas. El ultrasonido transvaginal ha revolucionado la evaluación en ginecología y en el primer trimestre del embarazo, lo cual ha permitido el diagnóstico de nuevas patologías.
\end{abstract}

Palabras clave: Ultrasonografía; Embarazo ectópico; Ginecología y Obstetricia. (Fuente: DeCS BIREME).

\begin{abstract}
Ectopic pregnancy is a gyneco-obstetric pathology whose management has changed today, going from being a purely surgical management pathology to a medical management entity with surgical indications. Transvaginal ultrasound has revolutionized evaluation in gynecology and in the first trimester of pregnancy, which has allowed the diagnosis of new pathologies.
\end{abstract}

Keywords: Vaginal Discharge; Leukorrhea; Candidiasis, Vulvovaginal; Trichomonas Vaginitis; Vaginosis, Bacterial. (Source: MeSH NLM).

\section{INTRODUCCIÓN}

El embarazo ectópico es una patología ginecobstetrica cuyo manejo ha cambiado drásticamente en los últimos 30 años, pasando de ser una patología de manejo netamente quirúrgico a una entidad de manejo medico con indicaciones quirúrgicas. En este proceso de cambio el ultrasonido ha cumplido un papel preponderante para hacer el diagnóstico precoz de esta enfermedad y propiciar el tratamiento oportuno y conservador.

\section{ULTRASONIDO TRANSVAGINAL EN GINECOLOGÍA Y OBSTETRICIA}

No quepa duda de que el ultrasonido transvaginal ha revolucionado la evaluación en ginecología y en el primer trimestre del embarazo, lo cual ha permitido el diagnóstico de nuevas patologías tales como: el istmocele, la malformación arteriovenosa uterina, el embarazo en cicatriz de cesárea, etc, y el manejo oportuno de los mismos.

Un examen de ultrasonido del embarazo temprano tiene tres objetivos principales: a) confirmar la ubicación y el número de embarazos, b) establecer si un embarazo normalmente implantado tiene el potencial de desarrollarse más allá del primer trimestre y c) evaluar el riesgo a la salud materna que plantea el embarazo ectópico.

En 1969 se desarrollaron los primeros transductores transvaginales bidimensionales, que rotaban 360 grados y fueron usados por Kratochwil para evaluar la desproporción cefalopélvica. Pero es en la década de los 80 s con la incorporación de las computadoras que las imágenes en escala de grises se pueden visualizar en tiempo real, lo cual ha revolucionado la evaluación y el diagnostico ginecológico.

Gracias a la sonda transvaginal es que se han podido establecer criterios diagnósticos para las diversas ubicaciones del embarazo ectópico, los cuales revisaremos incluyendo la casuística y la experiencia obtenida en los últimos años en el Departamento de Ginecología del Instituto Nacional Materno Perinatal (INMP).

\section{CRITERIOS DIAGNÓSTICOS DEL EMBARAZO ECTÓPICO TUBARICO ${ }^{1}$}

Al realizarse la evaluación con la sonda transvaginal se debe tener en cuenta lo siguiente:

1. Reacción decidual sin saco gestacional. El valor discriminatorio de la hCG por encima del cual se

Instituto Nacional Materno Perinatal. Lima, Perú

Jefe del Servicio de Medicina Reproductiva.

(D) Código ORCID: https://orcid.org/0000-0002-1279-3189, Luis Alberto Carpio Guzman

Citar como: Carpio Guzman LA. Criterios Ultrasonográficos del embarazo ectópico. Rev Peru Investig Matern Perinat. 2021;10(3): 42-46 DOI https://doi.org/10.33421/inmp.2021242 
debe observar saco gestacional intrauterino con un índice de confianza de $99 \%$ es $3510 \mathrm{UI} / \mathrm{L}^{2}$.

2. De no observarse saco gestacional se debe considerar un embarazo de localización indeterminada a d/c embarazo ectópico ${ }^{3}$.

3. Es necesario diferenciar la presencia del ovario de la del embarazo ectópico tubarico. La presencia de estructuras embrionarias y de latidos aumenta la sensibilidad y especificidad.

4. Presencia de cuerpo lúteo ipsilateral, que se observa en un $80 \%$ de los casos.

5. Presencia de líquido libre.

6. No olvidar que de tener duda mejor es esperar 48 horas y tomar una nueva medición de hCG-B antes de iniciar cualquier tratamiento.

7. La ß-HCG se incrementa como minimo en un embarazo viable cada $48 \mathrm{~h}$ : $>49 \%$ si hCG inicial es $<1500 \mathrm{UI} / \mathrm{L} ;>40 \%$ si hCG está entre 1500 a 3000 $\mathrm{UI} / \mathrm{L} ; \mathrm{y}>33 \%$ si hCG es $>3000 \mathrm{UI} / \mathrm{L}^{4}$.

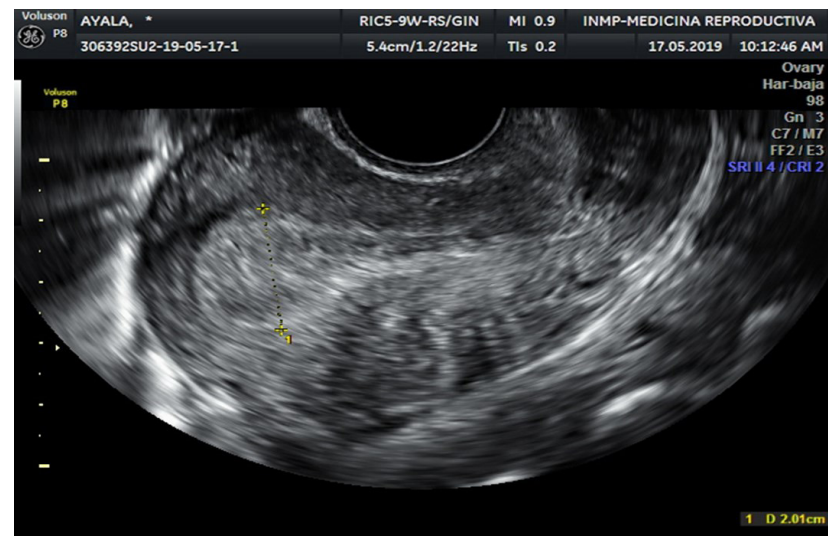

Figura 1. Paciente con retraso mesntrual de 9 semanas y valor de hCG-B de $18000 \mathrm{mUI} / \mathrm{L}$.

Observar la reacción decidual de $20 \mathrm{~mm}$ sin presencia de saco gestacional.

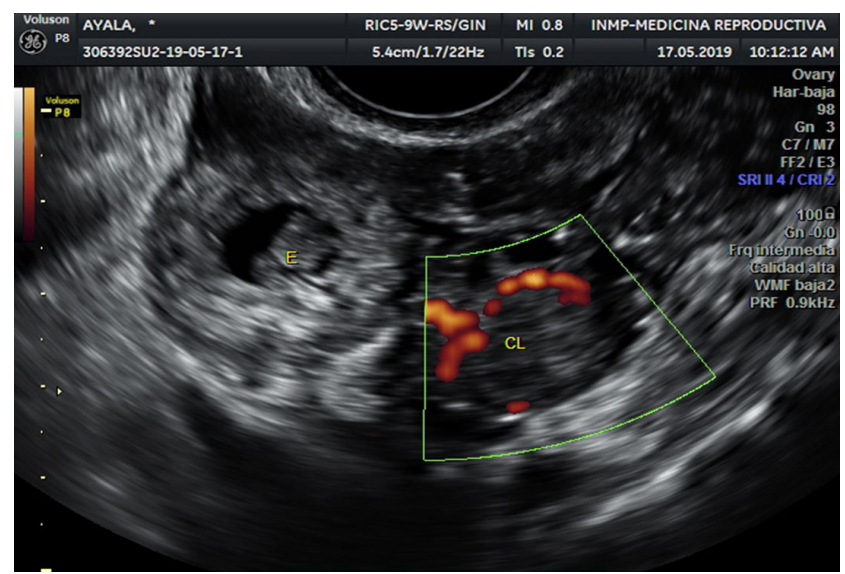

Figura 2. En la misma paciente se aprecia el ovario derecho con presencia de cuerpo lúteo $(\mathrm{CL})$, adyacente se observa una masa para ovárica con presencia de saco gestacional y embrión (E).

\section{CRITERIOS DIAGNÓSTICOS DEL EMBARAZO ECTÓPICO INTERSTICIAL}

El embarazo ectópico intersticial es aquel que se ubica en la porción intersticial o intramural de la trompa de Falopio a nivel del cuerno, por eso es que muchas veces se le denomina embarazo cornual.

Timor-Tritsch en el 1992, publica los criterios ultrasonográficos para diagnosticar el embarazo ectópico intersticial que son los siguientes ${ }^{5}$.

Criterios de Timor-Tritsch:

1) Cavidad uterina vacía.

2) Saco coriónica separados por lo menos $1 \mathrm{~cm}$ del borde lateral de la cavidad uterina.

3) Una fina capa de miometrio $(<5 \mathrm{~mm})$ que rodea el saco gestacional.

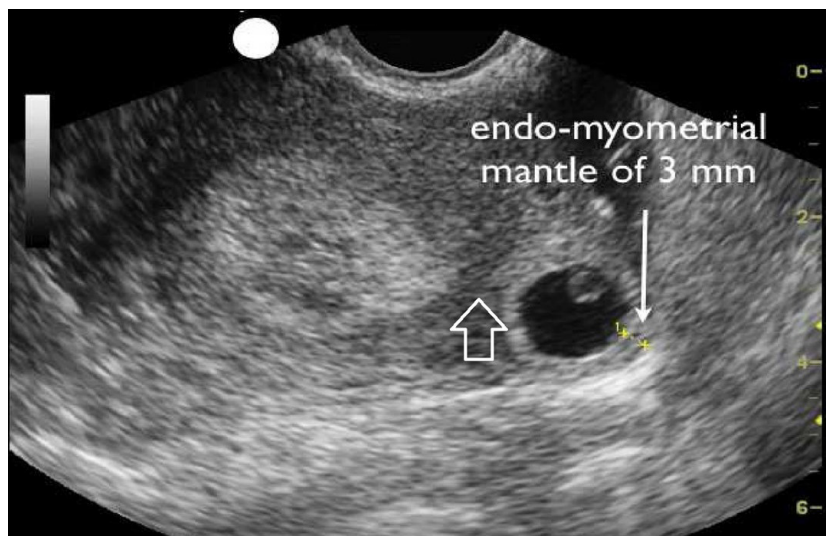

Figura 3. Embarazo intersticial. Observe la fina capa miometrial que circunda a la capa coriónica del saco gestacional y la distancia de la cavidad uterina al mismo.

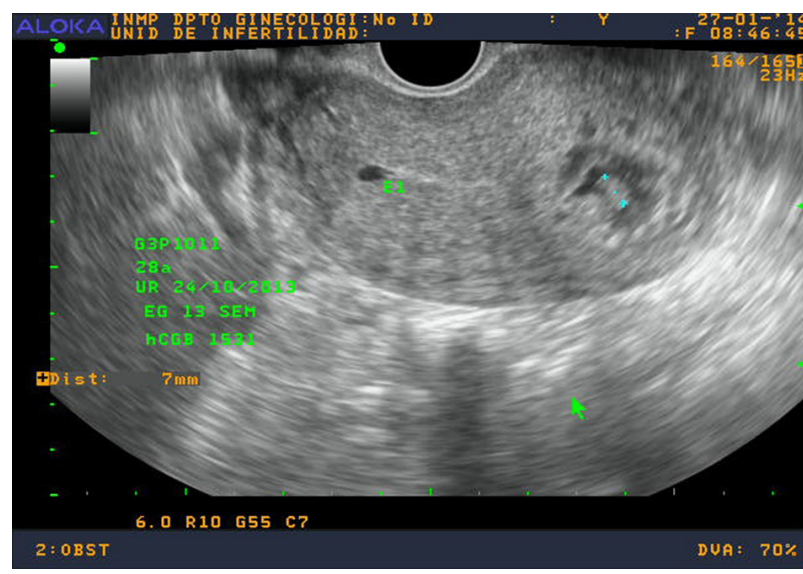

Figura 4. Paciente del INMP con diagnóstico de embarazo intersticial tratada medicamente con Metrotexato, que cumple los criterios de Timor-Trisch. 
El uso del ultrasonido volumétrico o 3D/4D, ha añadido una mejor forma de visualización para este tipo de embarazo ectópico, pues el corte coronal nos permite observar con mayor resolución la ubicación del saco gestacional y poder diferenciarlo del llamado embarazo intrauterino de implantación lateral o angular.

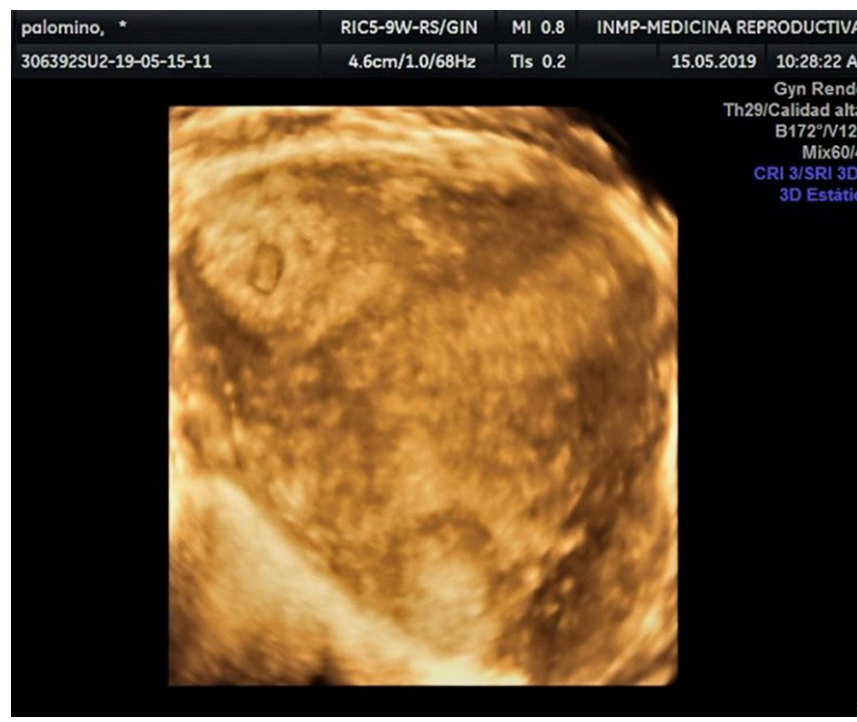

Figura 5. Visión coronal con ecografía 3D de un útero con presencia de saco gestacional y embrión a nivel intersticial derecho.

\section{EMBARAZO ECTÓPICO CERVICAL}

La prevalencia del EE cervical va de 1 en 8000 a 10,000 nacidos vivos, y aproximadamente es el $0.2 \%$ de todos los embarazos ectópicos ${ }^{6}$. En el INMP tuvimos en el año 2018 una tasa de 1/6000 nacidos vivos.

Ushakov en 1996 describe los criterios ultrasonográficos para el diagnóstico del embarazo cervical que son los siguientes:

1) Saco gestacional situado en el canal endocervical, entre el orificio cervical interno y el orificio cervical externo, por debajo de la entrada de las arterias uterinas.

2) Cavidad uterina vacía y con reacción decidual.

3) Invasión trofoblástica del tejido cervical confirmado con la flujometría Doppler.

4) Útero en reloj de arena o cérvix en forma de barril visto por vía abdominal.

5) Presencia de embrión o feto con latidos presentes que lo diferencia de un aborto en curso.

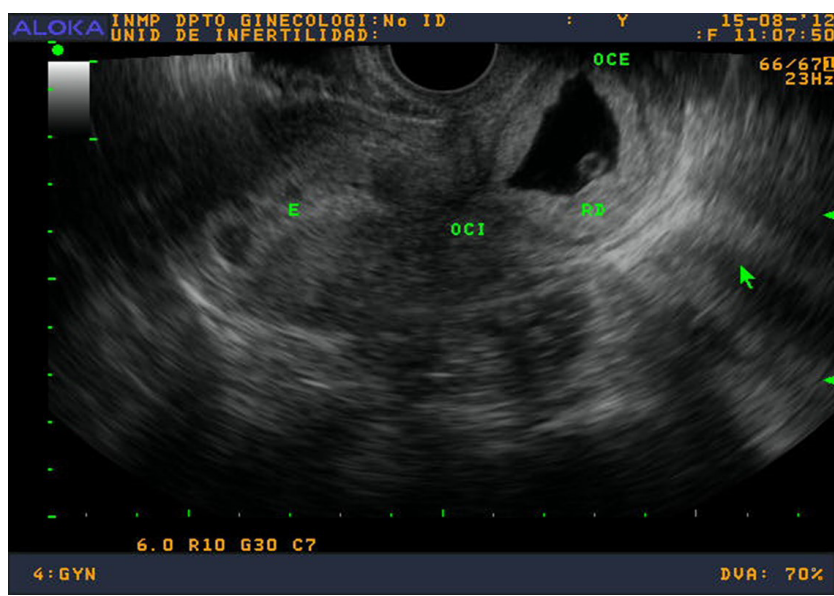

Figura 6. Se observa saco gestacional ubicado en el canal cervical entre el $\mathrm{OCI}$ y el OCE con presencia de saco vitelino.

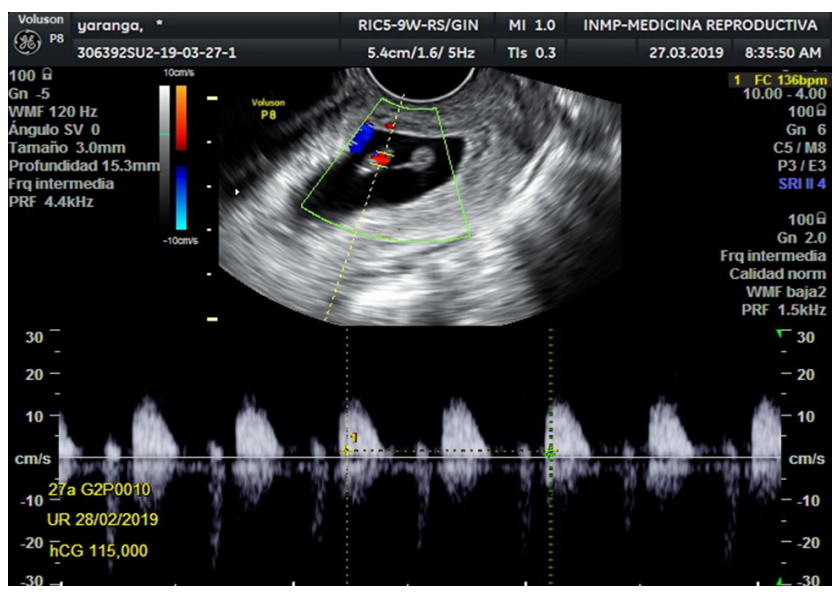

Figura 7. La presencia de latidos cardiacos en el embrión refuerza el diagnostico ya que lo diferencia de un aborto en curso.

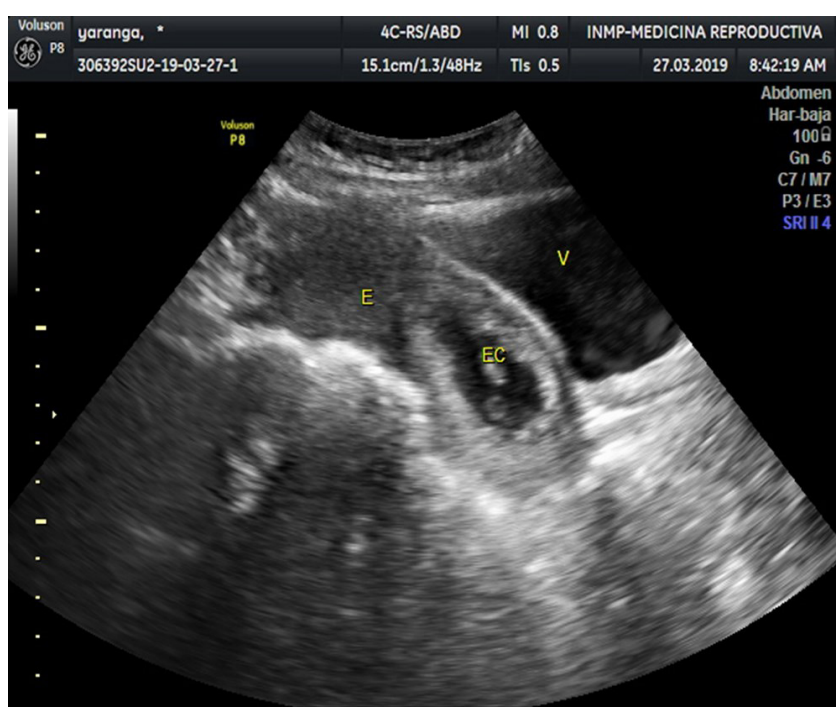

Figura 8. Útero en reloj de arena y cérvix en forma de barril, vistos por vía abdominal. 


\section{EMBARAZO EN CICATRIZ DE CESÁREA}

Desde que fuera reportado por primera vez por Larsen en 1978, su incidencia a nivel mundial se ha incrementado notablemente, siendo actualmente la 2da ubicación de embarazo ectópico luego de la tubárica, propiciado por el incremento del parto por cesárea ${ }^{7}$.

Vial en el año 2000 describe los siguientes criterios ultrasonográficos ${ }^{8}$ :

1) Implantación del trofoblasto entre la vejiga y la cicatriz de la cesárea.

2) Cavidad uterina y canal cervical vacíos.

3) Abombamiento de la pared a nivel del istmo uterino visto por vía abdominal.

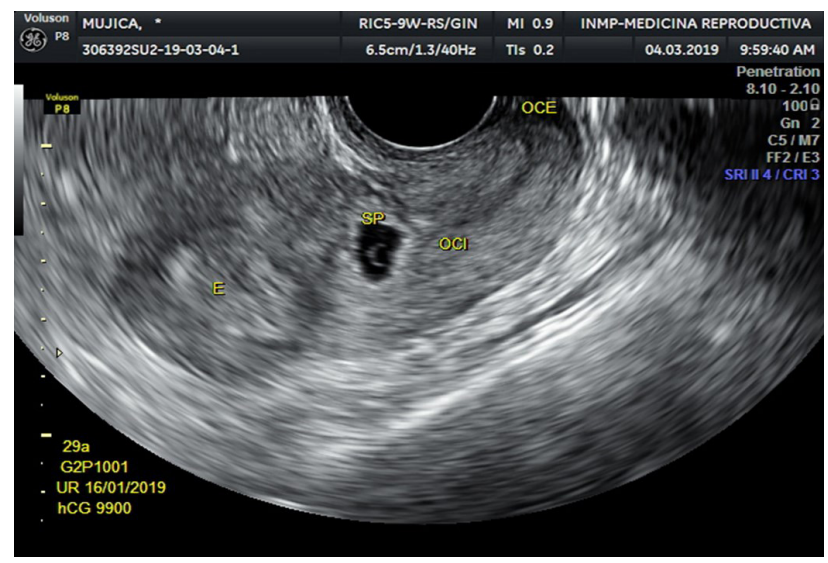

Figura 9. Observe el canal cervical vacío entre el OCl y el OCE, asimismo cavidad uterina vacía $(E)$. A nivel ístmico se aprecia saco gestacional con presencia de saco vitelino (SP).

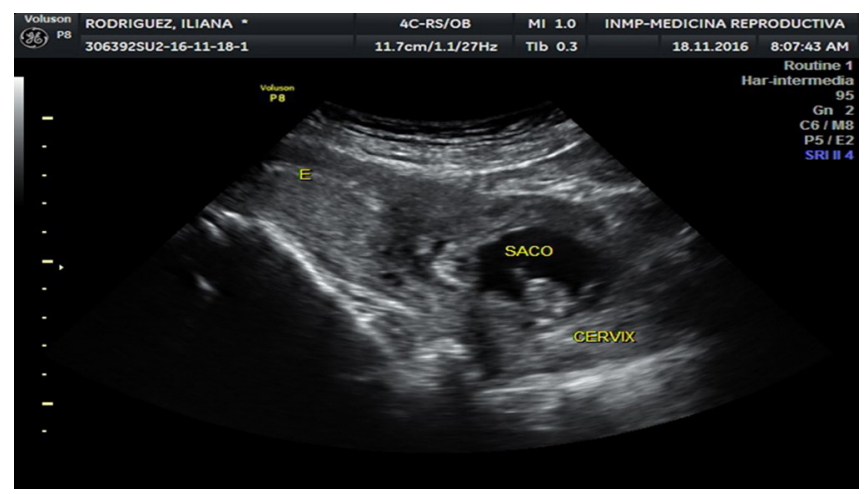

Figura 10. Por vía abdominal observe el abombamiento a nivel ístmico entre el cérvix y la vejiga observándose saco gestacional con presencia de embrión.

\section{EMBARAZO HETEROTÓPICO}

El embarazo heterotópico se define como la existencia simultánea de embarazo intrauterino y embarazo ectópico extrauterino. La incidencia de embarazo heterotópico en pacientes con un embarazo natural es de aproximadamente 1 en 8,000 a 1 en 30,000 embarazos. La principal ubicación extrauterina es la trompa, siguiendo en frecuencia la cicatriz de cesárea, la cervical y la intersticial ${ }^{9}$. Debido a los tratamientos de reproducción asistida, la incidencia de embarazo heterotópico va en aumento, variando de 1 en 100 a 1 en 3600 embarazos, con una prevalencia de $0.5 \%$ a $1 \%$ en todos los embarazos conseguidos por FIVI $\mid \mathrm{CSI}{ }^{10}$.

En el ultrasonido tenemos que confirmar con precisión la presencia de los dos sacos gestacionales en ambas ubicaciones.

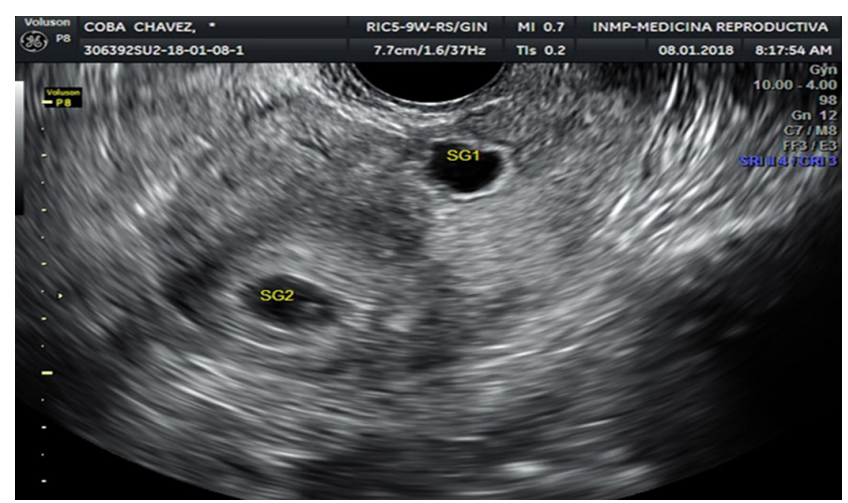

Figura 11. Observe la presencia de dos sacos gestacionales. EI SG1 a nivel de cicatriz de cesárea y el SG2 a nivel de cavidad uterina. El tratamiento del embarazo en cicatriz fue con $\mathrm{KCl}$ solamente y se pudo conservar la gestación intrauterina.

En conclusión, gracias al uso de ultrasonido transvaginal en tiempo real a partir de la década de los 80 , hemos conocido mejor la historia natural del embarazo ectópico en sus diferentes ubicaciones, lo que nos ha permitido realizar diagnósticos más precoces, certeros y de esta manera poder ofrecer tratamientos conservadores, no quirúrgicos o mínimamente invasivos (tratamiento local con Metotrexato y/o KCL). Es menester conocer los criterios diagnósticos por ultrasonido de estas patologías para lo cual es importante el entrenamiento en centros de referencia como el INMP y su divulgación a nivel de los programas de formación de especialistas.

Declaración de conflictos de intereses: El autor declara no tener conflicto de intereses.

Financiamiento: Autofinanciado.

\section{REFERENCIAS BIBLIOGRAFICAS}

1. Instituto Nacional Materno Perinatal. Guias de Practica Clinica y de Procedimientos en Ginecologia. Lima, Perú.2020. 
2. Connolly A, Ryan DH, Stuebe AM, Wolfe HM. Reevaluation of discriminatory and threshold levels for serum $\beta$-hCG in early pregnancy. Obstetrics and Gynecology. 2013 Jan;121(1):65-70.

3. Condous G, Timmerman D, Goldstein S, Valentin L, Jurkovic $D$, Bourne T. Pregnancies of unknown location: consensus statement. Ultrasound in Obstetrics and Gynecology [Internet]. 2006 Aug 1 [cited 2021 Aug 3];28(2):121-2. Available from: https://obgyn.onlinelibrary.wiley.com/doi/full/10.1002/ uog.2838

4. Barnhart KT, Guo W, Cary MS, Morse C, Chung K, Takacs $P$, et al. Differences in Serum Human Chorionic Gonadotrophin Rise in Early Pregnancy by Race and Value at Presentation. Obstetrics and gynecology [Internet]. 2016 Sep 1 [cited 2021 Aug 3];128(3):504. Available from: /pmc/articles/ PMC4993627/

5. IE T-T, A M, C M, CR V. Sonographic evolution of cornual pregnancies treated without surgery. Obstetrics and Gynecology [Internet]. 1992 Jun 1 [cited 2021 Aug 4];79(6):1044-9. Available from: https://europepmc.org/article/med/1579304

6. Yankowitz J, Leake J, ... GH-O\&, 1990 undefined. Cervical ectopic pregnancy: review of the literature and report of a case treated by single-dose methotrexate therapy. europepmc.org [Internet]. [cited 2021 Aug 6]; Available from: https://europepmc.org/article/med/2195408

7. Larsen J, Solomon M. Pregnancy in a uterine scar sacculus--an unusual cause of postabortal haemorrhage. A case report. undefined. 1978;

8. Vial $Y$, Petignat $P$, Hohlfeld $P$. Pregnancy in a cesarean scar [2] [Internet]. Vol. 16, Ultrasound in Obstetrics and Gynecology. Ultrasound Obstet Gynecol; 2000 [cited 2021 Jul 11]. p. 592-3. Available from: https://pubmed.ncbi.nlm.nih. gov/11169360/

9. Basile F, Cesare C di, Quagliozzi L, Donati L, Bracaglia M, Caruso A, et al. Spontaneous Heterotopic Pregnancy, Simultaneous Ovarian, and Intrauterine: A Case Report. Case Reports in Obstetrics and Gynecology. 2012;2012.

10. Dibble EH, Lourenco AP. Imaging Unusual Pregnancy Implantations: Rare Ectopic Pregnancies and More. http:// dx.doi.org/102214/AJR1515290 [Internet]. 2016 Aug 30 [cited 2021 Aug 21];207(6):1380-92. Available from: www. ajronline.org

\section{Correspondencia:}

Luis Alberto Carpio Guzman

Dirección: Jr. Joaquín Bernal 810 Lince

Correo: carpiog101@hotmail.com

Teléfono: 999352760 